\title{
A pedagogia de António Pinheiro
}

\section{Luís Gameiro}

\section{Quatro tópicos pedagógicos}

Começa por ser exigivel a leitura atenta da biografia de uma figura que se pretenda estudar. Assim, preparando um texto que viria a consistir numa dissertação de Mestrado, foram detectadas na leitura e sistemática consulta das suas três obras autobiográficas, quatro áreas fundamentais de trabalho, às quais António Pinheiro (Tavira, 21 Dezembro 1867 - Lisboa, 2 Março 1943) dedicara a sua energia e atenção. Se quisermos abreviar, sem prejuizo do que adiante se possa desenvolver, dir-se-ia que a carreira deste actor é pautada, em grande medida, pela Pedagogia. É com certeza óbvio - considerando que Pinheiro foi professor do curso de teatro do Conservatório - que o vocábulo se aplique. Mas a questão é bastante mais profunda.

Se António Pinheiro ocupou a cadeira de professor de Estética e Plástica Teatral, é porque, como afirmou o próprio, dedicava a essa área os seus "particulares e especiais estudos" (Pinheiro 1929: 229). 0 estudo da composição do corpo e do mecanismo da anatomia, dos tempos da Escola Politécnica, soube Pinheiro aplicá-los, na sua utilidade e em Portugal, à prática teatral, deixandoos de legado aos seus alunos, que trabalharam nos palcos do pais durante boa parte do século XX. A bibliografia da sua obra Estética e plástica teatral dá conta de quase seis dezenas de obras estrangeiras, quase todas em francês, de onde sobressai o carácter pioneiro desta obra e destes estudos em Portugal. A cadeira reúne também a análise e a correcta aplicação do guarda-roupa, dos acessórios, da caracterização, a que se juntam ainda estudos de encenação e exercícios de composição de personagens. Isto é, a cadeira ocupa-se da composição física e psicológica da personagem, até à sua movimentação no palco e à relação com as outras figuras e com o espaço.

Para que tal fosse realidade, foi preciso criar a Escola de Arte de Representar, a qual resulta de uma profunda reestruturação do ensino em Portugal. Nas justificações expressas no documento, que institui a Escola, percebese bem até que ponto o trabalho de reflexão e as batalhas associativas de António Pinheiro tornaram possivel a criação desse órgão de ensino.
0 associativismo, que António Pinheiro defendeu e praticou, tem a sua origem filosófica e histórica no Positivismo de Auguste Comte, divulgado em Portugal, principalmente, por Teófilo Braga, e é reorientado para o Teatro Português por António Pinheiro. A defesa dos direitos dos profissionais de teatro tornou-se uma realidade, graças à solidariedade e fraternidade que Pinheiro reputava indispensáveis. E foi com esses valores que António Pinheiro defendeu a união dos artistas.

À animosidade de empresários, juntou-se a reprovação de duas reformas elaboradas para o Teatro Nacional D. Maria II, as quais visavam a elevação "moral e artística" daquela casa, bem como a defesa dos artistas e da arte dramática portuguesa.

Estes objectivos só seriam atingidos através da actuação da Companhia Rey Colaço-Robles Monteiro, em cuja génese se encontra a figura do encenador António Pinheiro. Mas tornaram-se também conhecidos através da sua máscara de actor versátil, artista conceituado que passara por escolas como o amadorismo, o teatro ambulante e a formação profissional.

A Pedagogia, que António Pinheiro defendia, não se limitou ao ensino que ele reformulou e praticou. Toda a sua acção foi pedagógica, procurando - e deixando de legado - a disciplina, a elevação moral, a seriedade e o profissionalismo no trabalho dos artistas de teatro.

No campo do ensino, tendo trabalhado como professor durante cerca de trinta anos até 1939, justo será deduzir que todos os seus alunos terão usufruído das suas ideias, bem como das suas pesquisas no âmbito da prática teatral. Por conseguinte, é pertinente reflectir sobre o papel que terá tido na formação e na prática de várias gerações de artistas. Talvez a passagem de António Pinheiro pela arte de Talma tenha contribuido para permitir diversas carreiras de reputado valor. Mas vamos por partes.

\section{Um despertar sindicalista}

Datam dos primeiros anos do séc. XX várias reflexões de António Pinheiro em torno da qualidade do teatro português, a começar pela falta de profissionalismo e de seriedade com que actores e actrizes levavam a cabo o seu 
trabalho. Desenha-se então aqui a necessidade de o artista encarar a sua arte de forma profissional e com respeito para com os colegas, condições que iriam possibilitar uma associação de defesa dos artistas.

Pinheiro, que se notabilizara em 1900 na Companhia Rosas \&t Brazão, tem já nesta altura a experiência de artista ambulante em Portugal e no Brasil (este, com algumas especificidades que diferem do que entre nós se praticava), bem como de amador e alguns anos de profissional, além de ter feito o curso de teatro do Conservatório. Quer isto dizer que tem uma visão de considerável abrangência sobre o trabalho de actor, o que o coloca numa situação privilegiada para entender a profissão e as exigências que ela colocava ao artista.

Deste modo, com este caldo de experiências e aprendizagens diversas, e com um trabalho de reflexão certamente cuidado, António Pinheiro estava em condições singulares para reflectir sobre o associativismo no Teatro Português. E as conclusões, que tirou, evidenciavam o seu estado deplorável, face ao que, na época, o Montepio dos Actores representava na defesa da classe, única entidade do género, à excepção da Caixa de Socorros do Teatro Nacional D. Maria II, exclusiva para os artistas que pertenciam ao quadro do palco do Rossio. É então, no seio da companhia residente no Teatro D. Amélia, que, em 1902, funda a chamada Caixa de Socorros dos Artistas do Teatro D. Amélia. Esta iniciativa, de carácter particular, e exclusiva daquele teatro, foi polémica, suscitando, na imprensa, opiniões favoráveis e em sentido contrário. Mas constituía uma iniciativa para a defesa dos artistas do teatro, e também o início do debate em torno do associativismo da classe. De resto, Pinheiro entendia ser necessário propagar a ideia a outros espaços, oferecendo-se ele próprio para ser "a voz que lançaria a semente associativa a outras casas de espectáculos" (Pinheiro 1909: 48).

Esta experiência laboratorial desagua em 1908 na criação da Associação de Classe dos Artistas Dramáticos, de que é mentor, e em cuja génese está uma outra ideia que ele ligava à associação e que visava a preservação da memória dos artistas desaparecidos através da edificação de um mausoléu. Para a pôr em prática, António Pinheiro constituiu a Comissão dos Jazigos dos Actores Portugueses, que viria a estudar as bases para lançar uma associação de classe. António Pinheiro como presidente, Carlos Santos e Álvaro Cabral como secretários, assinam os estatutos da Associação cuja fundação "fez tremer de susto e lançou o pânico em todos os empresários teatrais do tempo" (Pinheiro 1929: 142), muito por culpa de um documento que Pinheiro redige, conhecido como Reivindicações da Classe dos Artistas Dramáticos. Nesse documento defende-se o descanso à 2 feira, adendas contratuais no caso de digressões, bem como épocas teatrais com nove meses de duração, respondendo assim, à diminuição tendencial que se vinha verificando. Este documento coloca o seu autor em rota de colisão com o Visconde São Luiz Braga, o qual, segundo Pinheiro, tem uma visão apenas mercantilista do teatro e entende os actores como limões: "Espremem-se até deitar suco. Depois, deitam-se para o lado como inúteis" (ibid: 28).

Esta imagem nada favorável do Visconde, considerado tradicionalmente como figura sabedora de teatro e de eterna bonomia, encontra sintonia em algumas considerações de Adelina Abranches e sobretudo de Lucinda Simões. Mas acabou por consistir num dos aspectos motivadores da dissertação, que procurou chamar a atenção, também, para factos raramente sublinhados, abrindo espaço para estudos posteriores, isto é, o Teatro e a sua História como um trabalho em processo. E essa é a beleza do trabalho de investigação, que pode ter resultados tão efémeros como o próprio espectáculo teatral.

Quanto a Pinheiro, se a Associação era vitoriosa ("as reclamações que se afiguraram de começo exageradas foram criteriosamente apreciadas" (ibid.: 173), o actor paradoxalmente, acaba por ser dispensado. A Associação cria a Caixa Económica Teatral e o Cofre de Beneficência, destinados a auxiliar os mais desfavorecidos, e estrutura um curso livre de teatro para educação de "artistas ou espectadores conscienciosos na análise das peças e interpretação" (Anon. 1909: 29). Da responsabilidade da própria direcção da Associação, o curso não tem, no imediato, grandes resultados. Mas por outro lado, implica - e transporta-nos inevitavelmente para - um outro plano da acção pedagógica de António Pinheiro. 

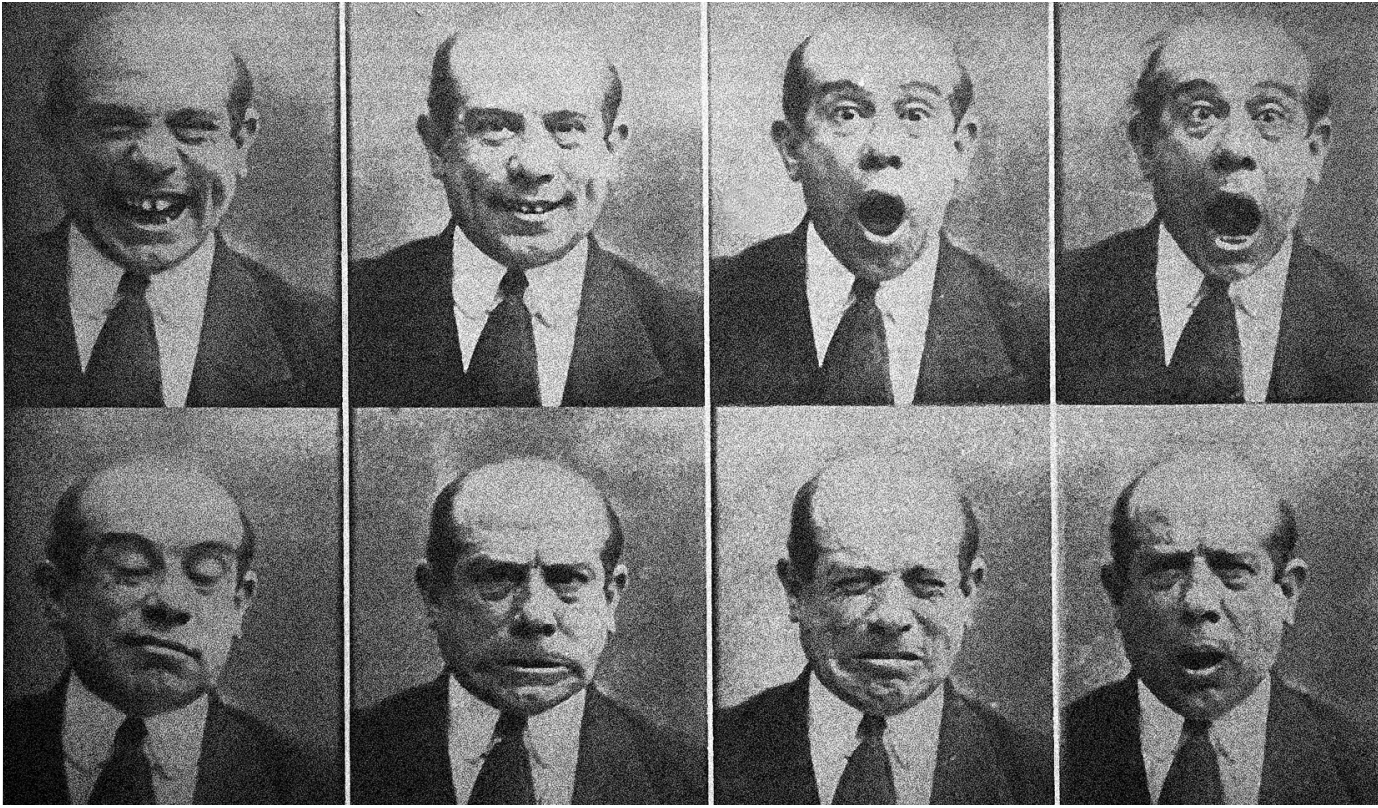

Reformar o ensino

0 ensino de teatro vem sendo objecto de reflexão por parte do actor que, com o curso livre da Associação, se pretende aproximar do que defende ser um curso apropriado. Pinheiro encontra no Governo Provisório da República um clima favorável à reestruturação do ensino da arte, que instituiria a Escola da Arte de Representar. E porque dizemos que é António Pinheiro que encontra esse clima favorável? Porque é este dirigente associativista que encontra no relatório, que institui a Escola, o eco das suas próprias e anteriores reflexões, expressas no texto Vocação e Arte - Para ser actor não basta ter vocação, é preciso ter arte.

Neste trabalho defendera a necessidade de mestres que moldassem a vocação no sentido da medida justa, e que desvendassem a cada discipulo "os segredos e as leis primordiais da arte a que vai professar culto" (Pinheiro 1909: 60). Em simultâneo, no mesmo texto detecta a deficiência de alguns actores, que se limitam a estudar e a saber de cor o seu papel, o que constitui "para o ensaiador, o mais penoso e amargurado dos trabalhos" (ibid.). Ora, segundo Pinheiro, a administração de noções de etnografia e psicologia, bem como de mímica, pantomima, estética e caracterização, contribuiriam para prover os artistas de mecanismos de estudo para a composição das figuras a que vão dar corpo, voz e alma. Essas são algumas das cadeiras reivindicadas no documento 0 theatro portuguez na actualidade, redigido em 1909 pelo próprio Pinheiro e por Simões Coelho, que o governo de Teófilo Braga, com a criação da Escola da Arte de Representar, leva em consideração, afirmando que procura "com esta reforma atender às conclusões apresentadas [...] pela Associação de Classe dos Artistas Dramáticos, sob a tese '0 Theatro Portuguêz na Actualidade'" (Anon. 1911: 9).

António Pinheiro acaba por ser nomeado professor de Estética e Plástica Teatral, matérias a que, como ficou referido, dedica particular atenção. Ensina Anatomia Plástica, Mímica, Pantomima e Caracterização, Indumentária, História do Vestuário e Sumptuária, Estética Dramática, Estética Teatral e Encenação. Promove visitas de estudo a locais como o Hospital Miguel Bombarda, onde os alunos vêem de perto "os estados de degenerescência e as psico-nevroses mais vulgarmente dramatizadas no teatro escandinavo" (Dantas 1914: 7).

Do seu exercício como professor de Estética e Plástica Teatral, importa reter o carácter inovador do seu trabalho no teatro português, bem como a capacidade de absorver do curso de Medicina - que frequentara - bases de sustentação para pesquisas e experiências no campo teatral, e que na Anatomia e, consequentemente, na Mímica e na Pantomima encontram a sua pertinência. Numa palavra, a seriedade na pesquisa e estudo para a correcta composição de uma figura "perfeitamente decalcada sobre a que o autor idealizou" (Pinheiro 1926: 354), ou não fosse António Pinheiro um defensor acérrimo da estética realista e naturalista.

\section{"Alvorada" naturalista?}

Este modelo de trabalho, que procura ensinar, e a preocupação com o estudo a partir do real estão em plena sintonia com a sua forma de estar no teatro enquanto artista. Veja-se o caso do espectáculo com o qual se notabiliza decisivamente, e que consiste na montagem de Viriato trágico de Júlio Dantas, levada a efeito pela Rosas Et Brazão em 1900, no Teatro D. Amélia. Quando António Pinheiro sobe ao palco como San-Vito, fica para trás toda uma investigação em torno da enfermidade desta personagem, valendo-se de livros emprestados pelo próprio Dantas, médico de profissão. San-Vito padece de coreia, uma degenerescência nervosa que leva à perda de coordenação motora e atrofia muscular por todo o corpo. Se na estreia, tendo em conta o testemunho do próprio Pinheiro, o público fez interromper um acto com aplausos e chamou ao palco o próprio autor, não é menos verdade que este considerou o San-Vito de Pinheiro a melhor das suas personagens em palco, como declarou em Janeiro de 1909 à llustração portugueza.

Na verdade, António Pinheiro seria um actor de grandes recursos, e se este episódio tende a demonstrar o empenho que colocava na preparação de cada personagem a encarnar, outros existem que dão conta da sua capacidade de improviso. Assim, antes de Viriato trágico, a companhia leva à cena A lagartixa de Georges Feydeau, em cuja estreia
António Pinheiro, in Cinéfilo, n. ${ }^{149}$ Junho de 1931 
Pinheiro terá substituido o seu colega Augusto Antunes no papel de General Petypon, sem que tenha assistido aos ensaios com atenção. Pinheiro faz corresponder esta situação com a prática adquirida no Brasil, isto é, o êxito do seu desempenho atribui-o à "aprendizagem e treino dos entalões em que me tinha visto nos mambembes" (Pinheiro 1924: 343).

Este tipo de teatro, com "fisionomia própria, psicologia especial, forma estética e fisiologia particulares" (Pinheiro 1912: 110), tem como origem remota a Commedia dell'Arte. $\mathrm{Se}$, nesta, a liberdade e o talento do actor permitem que ele represente a partir do "conhecimento de actos humanos observados na vida" (Moussinac 1972: 145) através do gesto, da mímica, da acrobacia, o actor de teatro mambembe casa esta tradição com um repertório ecléctico,

representando onde seja possivel improvisar um teatro. Pinheiro, que considera que o mambembe the aprimorou as qualidades artísticas, e que com ele aprendeu a "respeitar e a defrontar o público, sem temor, mas com amizade e brio" (Pinheiro 1912: 114), acaba por tirar partido dessa experiência para, no palco do D. Amélia, "salvar uma situação dificil a uma empresa" (Pinheiro 1924: 346).

$\dot{E}_{1}$ de resto, interessante verificar que estas duas formas de trabalhar tão distintas se tenham passado no mesmo palco e com os mesmos intervenientes à distância de um mês. E mais interessante será fazer o paralelo entre esta curiosidade e a própria Companhia Rosas \&t Brazão, enquanto local onde se joga uma transição entre a tradição romântica e o Naturalismo. Assim afirma Vitor Pavão dos Santos, sublinhando ainda que o artista de teatro, "à luz das novas tendências, encarrega-se tanto de um pequeno papel como o de um protagonista" (Santos 1979: 8). Naturalmente, deve verificar-se que tal fenómeno não corresponde ao espaço temporário de dois espectáculos consecutivos, muito menos presumir-se que 1900 consista numa espécie de ano zero do Naturalismo. Contudo, não deixará de ser curioso este paralelo, como que a reclamar o local mais notório de conquista de terreno do Naturalismo face ao Romantismo em palco.

\section{Encenação e Teatro Livre}

0 palco do Teatro D. Amélia é aquele que vê nascer o encenador António Pinheiro. É verdade que já em 1895/96 experimentara a encenação no Teatro Príncipe Real, mas é na temporada de 1901/02 que inicia, de forma consistente, o seu trabalho nesta área. 0 homem que lhe guia estes passos, a quem auxilia, é José António Moniz, figura que o próprio António Pinheiro recorda com estima e consideração, e que nesta altura se encarrega, na Rosas \& Brazão, da direcção de cena. Filho de um discipulo de Émile Doux, Moniz é ensaiador na companhia entre 1898 e 1906. Segundo o próprio Pinheiro, este ajuda Moniz na direcção de ensaios, bem como, afirma, "marcando e ensaiando peças em um acto", sendo a primeira, Mensageiro da paz,
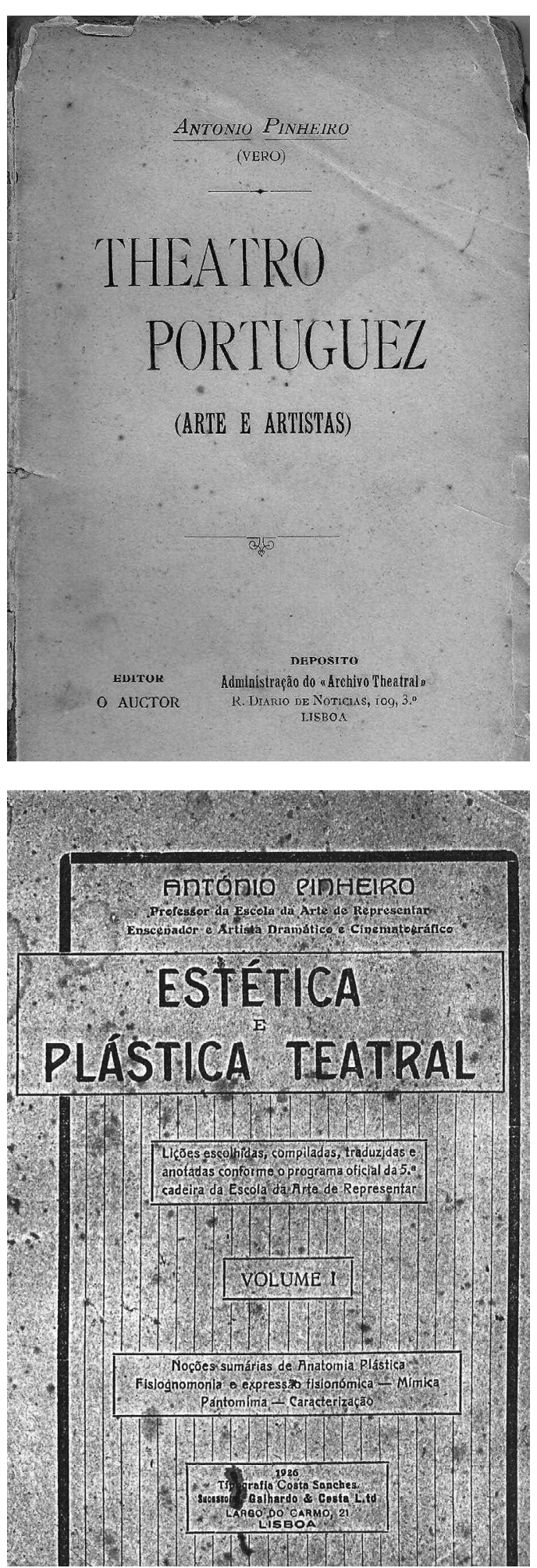

que enceta uma série de críticas positivas ao longo dos seus anos de trabalho como ensaiador na Rosas \&t Brazão até deixar esta companhia em 1910.

Se é verdade que é o trabalho de marcação que mais facilmente fica registado para a posteridade, então será justo reputar António Pinheiro da melhor forma. Como curiosidade, o Diário de notícias refere, em 1928, que Pinheiro terá marcado no espaço de um ano um total de 102 actos, o que constituiria um recorde, enquanto 0 próprio Pinheiro contabiliza de 1902 a 1928, cerca de 
2500 actos. Serão apenas números, mas será lícito que se entenda em António Pinheiro um grande profissional, não só pela contabilidade, mas também pela sua passagem notória em várias companhias, no Teatro Livre e no Teatro Nacional D. Maria II, como adiante iremos verificar.

Vejamos, por enquanto, o que nos diz Pinheiro sobre marcação, começando por afirmar que defende para um bom marcador vastos conhecimentos de psicologia e sociologia. Acrescenta Pinheiro:

"um estudo aprofundado sobre os caracteres e temperamentos; justa e perfeita noção dos meios sociais, dos tipos, dos individuos;

familiaridade com a história, com a arqueologia, com a acústica, com a óptica, com a perspectiva e, para remate final, ciência certa e exacta da estética teatral e da encenação" (Pinheiro 1913: 19). Sublinha ainda que a marcação se prende com "o lugar que cada figura ocupa na cena, as entradas e saidas, os movimentos que cada personagem executa parcialmente e em relação às demais figuras, a disposição total e movimentada de quadro vivido ou fantasista que a peça tenta reproduzir e que a marcação e a encenação vão viver" (ibid.).

É verdade que quando o encenador chega ao Teatro Livre, este tivera já a sua primeira época, inaugurada com um espectáculo que Joaquim Madureira diz marcar, "na História do Teatro e da História das ideias em Portugal, uma data de luz e de esperanças", levada a efeito por "um grupo de rapazes de ideias sãs e vistas largas" (Madureira 1905: 313). A veiculação de ideias em que o Teatro Livre aposta, sendo o famoso mote "transformar pela arte, redimir pela educação", significa que a dramaturgia, que sugere, rompe com os modelos tradicionais, na senda de Antoine, que deixara em Portugal "sulcos profundos de boa e rude Arte" (ibid. 92), como escrevera Joaquim Madureira.

Neste sentido António Pinheiro que, como se referiu, é próximo das novas tendências, assume na segunda época a direcção artística da sociedade. No Teatro Ginásio, consegue "alcançar magníficos conjuntos" que terão contribuído "para o êxito dos espectáculos" (Pinheiro 1929: 113). E se é facto que António Pinheiro encontrou os meios que exigiu para trabalhar as encenações, também é verdade que soube, das mesmas, tirar o melhor proveito artístico. A sociedade, em público elogio, refere "prodígios de arte cénica", "rara perícia e valor artístico" ou ainda "trabalho colossal, tanto intensivo como extensivo e imensamente artístico." (apud Pinheiro 1929: 115).

\section{A República no Teatro Nacional}

É de levar em consideração a hipótese de António Pinheiro ter assumido o lugar de encenador na Casa de Garrett, após a implantação da República, por ser "republicano ferrenho". A sua passagem pelo Teatro Livre, em 1905, talvez tenha contribuido decisivamente, não só para uma reputação artística como também a de republicano convicto. As linhas programáticas do Teatro Livre e do
Naturalismo fundem-se com as ideias republicanas, tal como defendem Glória Bastos e Ana Isabel Vasconcelos (Bastos / Vasconcelos 2004: 134). Ora, o Teatro Livre tem, entre os seus fundadores, "reconhecidos republicanos", como é o caso de Teófilo Braga. Então, há uma movimentação de tendências e influências onde se joga, no Teatro, a propaganda republicana, em cujo tabuleiro António Pinheiro tem um papel de relevo.

Ao chegar ao Teatro Nacional, Pinheiro encontra um cenário de intriga, rivalidades, gestão incompetente, aspectos que Pinheiro afirma serem realidade desde que a sala do Rossio abrira ao público. De resto, Matos Sequeira, nas páginas da sua História do Teatro Nacional D. Maria II, acaba por ir ao encontro desta opinião, excepção feita aos anos do comissário Francisco Palha, entre 1862 e 1865.

É com a Proclamação da República que alegadamente existe no ar um ambiente de agitação e renovação, "revelador de homens e de ideias" (Sequeira 1955: 483). Pinheiro entra como societário a 3 de Novembro de 1911, ano em que, em Fevereiro, surgira um pedido de intervenção urgente no Nacional, da responsabilidade da Associação de Classe dos Artistas Dramáticos. Esta entende que o Teatro Nacional se encontra num estado gravoso "para os interesses económicos dos artistas", para além de os poderes de decisão estarem entregues a entidades que podem "não possuir os conhecimentos práticos e profundos da especialidade" (Pinheiro 1929: 206). Dias depois, a 11 de Fevereiro, é nomeada uma Comissão de Inquérito para "apresentar ao Governo os alvitres" tendo em vista a reforma do Teatro Nacional Almeida Garrett, para beneficio dos "legítimos interesses da Arte, da Literatura e dos artistas dramáticos portugueses" (ibid.: 207). Encabeçada pelo Director Geral de Instrução, a Comissão é constituída por dez outros elementos, procurando dar voz aos vários quadrantes da vida teatral portuguesa, pelo que António Pinheiro surge como representante da Associação a que preside. Se a composição desta comissão procura abranger os diversos pontos de vista profissionais, tal facto acaba por resultar infrutífero. Os trabalhos nunca foram concluídos, porque bloqueados pela impossibilidade de uma verba estatal para a exploração do Teatro.

Em simultâneo, o comissário António Pinheiro e o ensaiador Augusto de Melo travam batalhas de argumentos que são expressos e justificados nas páginas da imprensa e em sessões de esclarecimento. Por trás desta polémica está, alega Melo, uma reforma que Pinheiro tem na manga, e que implicaria ser-Ihe reservado o lugar de encenador, mas essa troca de galhardetes encerra-se com a entrada de Pinheiro como societário.

Na mesma data, 11 de Fevereiro, o Governo faz dissolver o Conselho de Arte Dramática que substitui pelo Conselho Teatral, órgão que tem também um representante da Associação, responsabilidade que recai, uma vez mais, em António Pinheiro. 


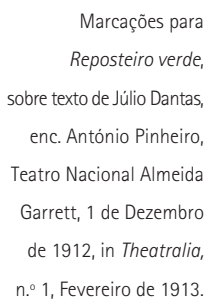

Durante a temporada de 1911-1912, este conselho elabora um projecto de reforma para o Teatro Nacional, através de uma subcomissão constituída por Pinheiro, Júlio Dantas e Luís Barreto da Cruz. Todavia, a polémica é retomada. De um lado está António Pinheiro que, diz Matos Sequeira, "dispunha de certa influência naquela ocasião" (Sequeira 1955: 496). De outro, o artista Inácio Peixoto, amigo de França Borges, o qual Ihe põe à disposição uma coluna em 0 mundo. 0 cerne da questão, o chamado Quadro Extraordinário, abriria espaço para que artistas de outros teatros acabassem agregados ao Nacional em jeito de "lista de espera" aguardando uma vaga de societário. Além disso, ficariam habilitados a ser socorridos em caso de invalidez, ao fim de vinte anos no mesmo quadro. Ora o Estado, suportando 95\% das contribuições para o cofre, libertaria - como até então - tais encargos do bolso dos societários. De um lado Peixoto, que defende o Quadro Extraordinário como sendo "uma armadilha feita aos artistas", do outro o Visconde São Luiz Braga, receoso de um desfalque na sua companhia, acabam por exercer com êxito a influência para anular tal medida, e a reforma é publicada com excepção de todas as medidas relativas ao polémico quadro. 0 mesmo diploma institui o Conselho de Gerência, presidido por Augusto de Castro, secundado por Joaquim Costa, gerente-delegado; Luis Pinto, tesoureiro; Carlos Santos, secretário e António Pinheiro, director de cena.

Cerca de dois anos de trabalho nas mais precárias condições e pautados por intrigas, "permanentes dissídios", consequentes desentendimentos e falta de união, prejudicam a arte e os seus praticantes, afinal, tudo o que é contrário às ideias defendidas por António Pinheiro, que outra saida não encontra que não a demissão de societário. A ideia de Pinheiro do Quadro Extraordinário não vinga e, como diz Matos Sequeira, "o que se passaria se ele tivesse ido por diante, é que não é fácil de adivinhar." (Ibid.: 498). De todo o modo, à reforma de 1912 faltou subtrai-la dos interesses individuais, das paixões e dos extremismos, que Pinheiro afirma serem inimigos da obra "forte e fecunda."

Resulta das falhas desta reforma, um ambiente de caos e de indisciplina geral, que leva a uma situação limite do Nacional: "desconjunta-se por todos os lados." (Ibid: 551). Em 12 anos o Teatro Nacional conhece quase três dezenas de decretos reformadores, os quais não põem termo às dissidências, obrigando mesmo ao seu encerramento em Janeiro de 1926, e à extinção da sociedade artística.

Esta resenha histórica, este "lindo pé de campanha", nas palavras de António Pinheiro, onde se jogam "ambições, desejos, interesses, assaltos" (Pinheiro1929: 441), é afina não só uma história secular de rivalidades, que remonta ao tempo em que o teatro da Rua dos Condes e o do Salitre disputavam o título de Nacional. É também o retrato de um pais e das suas permanentes convulsões no estertor da Primeira República.

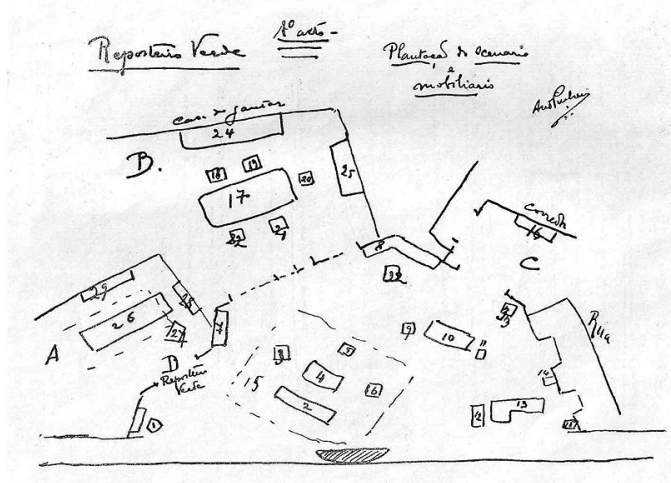

A expressão irónica do actor e encenador, registada no seu livro Contos largos..., acompanha vasta reprodução de textos de imprensa e entrevistas, como acontece inúmeras vezes no decorrer das páginas das suas obras autobiográficas. Todos estes e outros artigos deveriam ser confrontados com a imprensa da época o que, em boa verdade, não é possível em todos os casos, tendo em conta os periódicos existentes nos arquivos. Resta-nos encarar as reproduções impressas como fontes primárias, seleccionadas e dispostas por alguém que defendia a verdade, a honestidade, a seriedade.

Trabalhadores de teatro por um lado, e escritores e compositores por outro, assumem estudos para reformar - uma vez mais - o Nacional. Por parte dos primeiros, o incontornável António Pinheiro preside à comissão de Representação Oficial do Grémio dos Artistas Teatrais, instituição de que redigira os estatutos em Janeiro de 1918, depois de pressionado por uma assembleia de artistas no Éden-Teatro, em Julho do ano anterior. A Associação de Classe dos Artistas Dramáticos encerrara em 1914, e quatro anos depois é instituida a Associação de Classe dos Trabalhadores de Teatro, posteriormente designada Grémio dos Artistas Teatrais, na consequência do recolher obrigatório decretado e, por conseguinte, do encerramento dos teatros, situação que levara à referida reunião no Éden.

Voltando ao palco do Rossio, o projecto do Grémio é a um tempo, aprovado e inviabilizado por razões que se prendem com o Tesouro Público, o qual não comportaria o caminho da administração directa pelo Estado que o projecto defendera. Pinheiro demite-se da Comissão e do Conselho Teatral e, quanto ao palco, fecha portas a 30 de Setembro de 1926.

\section{Na génese da estabilidade}

A estabilidade e reputação positiva só chegam ao Teatro Nacional com a sua adjudicação à Companhia Rey ColaçoRobles Monteiro. Como primeiro espectáculo, em Dezembro de 1930, a companhia leva à cena Peraltas e sécias de Marcelino Mesquita, com encenação de António Pinheiro. Todavia, o envolvimento do encenador com a companhia tem início em datas anteriores.

Em Fevereiro de 1921 é chamado à encenação de Zilda, de Alfredo Cortez, pela sociedade artística do Teatro Nacional. Este espectáculo, que sobe ao palco 50 vezes, colhe 0 agrado do público e o reconhecimento do autor, que refere "inteligência e alto critério" na montagem do espectáculo, por parte de António Pinheiro, a quem chama "grande mestre do Naturalismo." (apud Palhinha 1986: 4). 

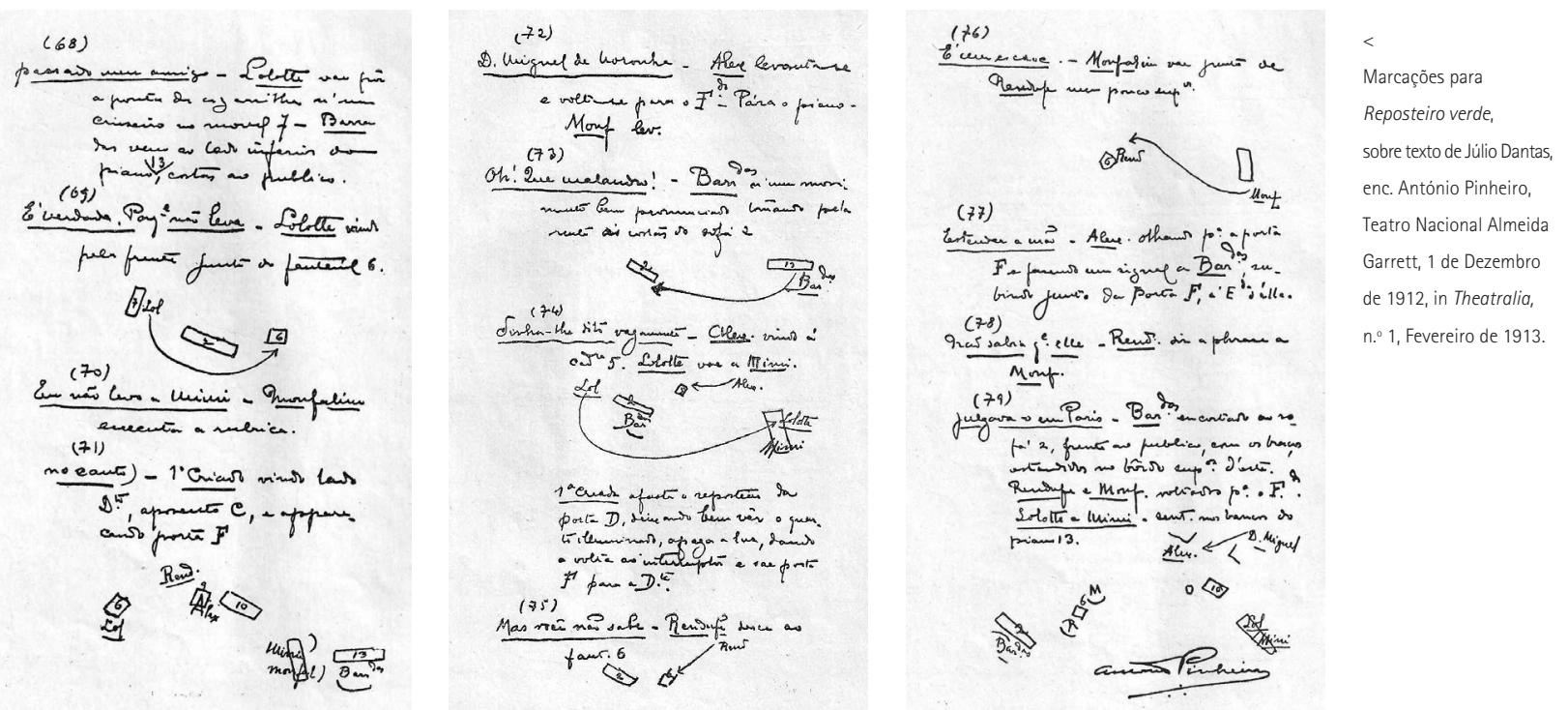

Aproveitando este sucesso, que não obstante devese também ao desempenho de Amélia Rey Colaço, a companhia, de que esta é titular, inicia a sua actividade no palco do S. Carlos em Junho do mesmo ano, com uma montagem de Zilda feita pelas mesmas pessoas lideradas por António Pinheiro, repetindo o casal Rey Colaço Robles Monteiro os seus papéis. Dias depois estreia Marianela dos irmãos Quintero, que fora um êxito no Teatro República em 1917, e que consistiu na estreia em palco de Amélia Rey Colaço. Tanto em 1917 como agora, em 1921, a encenação é da responsabilidade de António Pinheiro, que assim inscreve o seu nome e o seu trabalho no arranque da Companhia Rey Colaço-Robles Monteiro, contribuindo deste modo para a reputação desta. De resto, os quatro espectáculos seguintes são também da sua lavra enquanto encenador: Entre giestas de Carlos Selvagem, Sedutores de Vasco Mendonça Alves, Jerusalém de Georges Rivolet e Os lobos de João Correia de Oliveira e Francisco Lage. A partir de 1928 no Trindade e principalmente a partir de 1930 no Nacional, a colaboração do encenador com a Companhia torna-se mais consistente, mesmo como actor, profissão de que se despede em 1933, dando vida ao Cardeal D. Henrique de D. Sebastião de Tomás Ribeiro Colaço.

Se António Pinheiro iniciou artisticamente e dirigiu os primeiros passos da Companhia Rey Colaço-Robles Monteiro, como afirma o próprio, é lícito pensar que emprestou ao grupo e aos seus êxitos o seu pensamento, as suas ideias, a sua experiência. Será justo, desse modo, que se pense que na construção do sucesso, da reputação e do respeito pela Companhia, existe um degrau chamado António Pinheiro, pedagogo que nos palcos e fora deles insistiu na "elevação moral e artística", subsídios que deixa de legado ao teatro português.

\section{Referências bibliográficas}

Anon. (1909), Annuario da Associação dos Artistas Dramáticos 1908, Lisboa, Typographia do Archivo Theatral.

-- (1911), Instituição da Escola da Arte de Representar, Lisboa, Imprensa Nacional.

BASTOS, Glória / VASCONCELOS, Ana Isabel (2004), 0 teatro em Lisboa no tempo da Primeira República, Lisboa, Museu Nacional do Teatro.
DANTAS, Júlio (1914), Escola da Arte de Representar - Relatório do Director - Ano Lectivo de 1912-1913, Lisboa, Imprensa Nacional.

GAMEIRO, Luis (2011), António Pinheiro: Subsidios para a história do teatro português. Dissertação de Mestrado apresentada à Faculdade de Letras da Universidade de Lisboa (texto policopiado).

MADUREIRA, Joaquim (1905), Impressões de theatro, Lisboa, Ferreira \& Oliveira.

MOUSSINAC, León (1972), História do teatro das origens aos nossos dias, Amadora, Livraria Bertrand.

PALHINHA, Margarida (coord.) (1985), A Companhia Rey Colaço-Robles Monteiro, Lisboa, Museu Nacional do Teatro.

PINHEIRO, António (1909), Theatro portuguez: Arte e artistas, Lisboa, Tipografia do Archivo Teatral.

-- (1912), Ossos do ofício..., Lisboa, Livraria Bordalo.

-- (1913), "A Marcação" in Theatralia n. 1, pp. 19-24.

-- (1924), Coisas da vida..., Lisboa, J. Rodrigues \& Ca.

-- (1926), Estética e plástica teatral, Volume I [-], Lisboa, Tipografia Costa Sanches.

-- (1929), Contos largos... Lisboa, Tipografia Costa Sanches.

REBELLO, Luiz Francisco (2010), Três espelhos. Lisboa, Imprensa NacionalCasa da Moeda.

SANTOS, Vitor Pavão dos (1979), A Companhia Rosas \& Brasão 1880-1898. Lisboa, Secretaria de Estado da Cultura.

SEQUEIRA, Gustavo de Matos (1955), História do Teatro Nacional D. Maria II. Lisboa, Teatro Nacional D. Maria II.

\section{Periódicos consultados}

Diário de Lisboa (Ed. João Chrysóstomo de Sá), 18 Dezembro 1937. Diário de notícias (Dir. Eduardo Schwalbach), 28 Maio 1928.

Grande Elias, O (Ed. Thomaz Rodrigues Mathias), 14 Julho 1904. Ilustração portugueza (Ed. António Maria Lopes), 6 Agosto 1921; 10 Novembro 1919.

Palco, O (Ed. da Cunha e Sá), 5 Março 1912.

Século, O (Ed. António Maria Lopes), 2 Fevereiro 1939; 3 Março 1943. Sinais de cena (Dir. Maria Helena Serôdio), Fevereiro 2004; Dezembro 2010. Theatralia (Ed. Francisco Lage), Fevereiro 1913. 



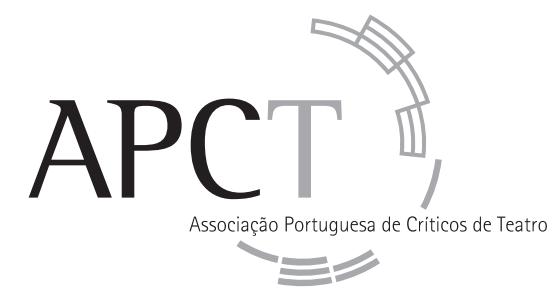

\begin{tabular}{l|l} 
Direcção & $\begin{array}{l}\text { Maria Helena Serôdio } \\
\text { João Carneiro } \\
\text { Rui Pina Coelho }\end{array}$
\end{tabular}

Assembleia Gera

Alexandra Moreira da Silva

Sebastiana Fadda

Conselho Fiscal

Ana Isabel Vasconcelos

Mónica Guerreiro

Rita Martins

Capitulo Primeiro (Da Associação e dos seus fins)

ESTATUTOS

Art. ${ }^{\circ}{ }^{\circ}$

\section{A Associação tem por objectivo:}

Dignificar, estruturar e responsabilizar a actividade crítica relativa à teoria e prática do teatro, entendendo-se por actividade crítica não só a crítica de espectáculos, mas também tudo aquilo que diga respeito à informação, reflexão e teorização no campo das artes performativas.

\section{Colaboração com Sinais de cena}

A revista está aberta à participação de quem deseje colaborar enviando artigos que julgue corresponderem aos objectivos da publicação e às modalidades enunciadas pelas rubricas existentes. A consulta do sítio da APCT na Internet (www.apcteatro.org) e o contacto por correio electrónico (estudos.teatro@fl.ul.pt) são indispensáveis para conhecer as normas de apresentação dos artigos (dimensão, aspecto gráfico, citações, referências bibliográficas, ilustrações, etc.).

\section{ASSINATURA}

Desejo subscrever os números 20 e 21 da revista Sinais de cena (correspondentes a Dezembro de 2013 e Junho de 2014), no valor total de $22,00 €$ beneficiando assim de um desconto sobre o preço de venda ao público.

Fora do pais: Europa $24,00 €$ / Fora da Europa $26,00 €$.

Nome:

Morada:

\begin{tabular}{l|l} 
Código postal: & Pais:
\end{tabular}

\section{Endereço electrónico:}

\begin{tabular}{ll|l} 
Forma de pagamento: $\quad \square$ Vale postal $\quad \square$ Cheque $n^{\circ}$. & Banco
\end{tabular}

(passar à ordem de Associação Portuguesa de Críticos de Teatro)

Preencha e envie este cupão (ou fotocópia do mesmo) para: 